\title{
Control of product nature and morphology by adjusting the hydrogen content in a continuous chemical vapor deposition process for carbon nanotube synthesis
}

Yang Ma, ${ }^{1 \pm}$ Anthony B. Dichiara,${ }^{2{ }^{* \pm}}$ Delong He, ${ }^{1}$ Laurent Zimmer, ${ }^{3}$ Jinbo Bai ${ }^{1^{*}}$

${ }^{1}$ Laboratoire MSSMat, CNRS UMR8579, CentraleSupélec, Université ParisSaclay, Grande Voie des Vignes, 92295 Châtenay-Malabry, France

${ }^{2}$ School of Environmental and Forest Sciences, University of Washington, Seattle, WA 98195, United States

${ }^{3}$ Laboratoire EM2C, CNRS UPR288, CentraleSupélec, Université Paris-Saclay, Grande Voie des Vignes, 92295 Châtenay-Malabry, France 


\section{Abstract}

Floating catalyst chemical vapor deposition (FCCVD) is commonly considered as one of the most attractive process for the production of carbon nanotubes (CNTs). Understanding the phenomena occurring during the FCCVD synthesis of CNTs is critical to improve the process selectivity and scalability. The present work correlates information on gas chemistry and structural characteristics of the carbonaceous products, and show how both are strongly related to the hydrogen content in the reactor. Hydrogen plays different roles in the CNT growth process whose contributions depend on the synthesis conditions. Its presence induces an augmentation in carbon supply by promoting the decomposition of hydrocarbon vapors into more reactive byproducts, and by serving as an activation agent for the dissociation of physisorbed hydrocarbons on the surface of catalyst particles. However, high hydrogen content can induce catalytic hydrogenation of carbon and lead to surface modification of CNTs. Hydrogen also interferes with the decomposition of catalytic precursors, thus influencing the size and availability of catalyst nanoparticles. As a result, the mean and core diameters, crystallinity of the graphene walls, and length of CNTs are greatly influenced by the hydrogen flow, which offers the possibility to tune the CNT properties in a very simple, yet efficient way. 


\section{Introduction}

Comprised of one or several sheets of hexagonally packed carbon atoms rolled into concentric seamless cylinders, carbon nanotubes (CNTs) exhibit extraordinary properties that make them highly desirable for a wide range of applications from energy storage $[1,2]$ to environmental remediation $[3,4]$ and structural composites $[2,5]$. The properties of CNTs, such as conductivity, thermal stability, stiffness, and surface area are determined by their length, diameter, wall numbers and how the carbon atoms are arranged within the graphene wall [6]. However, the ability to produce CNTs with specific and uniform properties at a large scale still remains an unsolved challenge and often requires several post-treatment steps [7].

Among the different synthesis methods, floating catalyst chemical vapor deposition (FCCVD) is an easily-scalable, one-step, continuous technique which has already been adopted by several companies [8]. This process involves the simultaneous injection of hydrocarbon and catalytic precursors into a reactor at temperatures ranging from 800 to $1200{ }^{\circ} \mathrm{C}$ in a reducing atmosphere[9, 10]. Ferrocene is one of the most commonly used catalytic sources due to its good stability, low cost and non-toxicity [11]. Thermal decomposition of ferrocene leads to the nucleation of iron particles, where decomposed carbon can diffuse, precipitate and assemble into tubular structures. As CNTs begin to grow, they preferentially bundle due to attractive Van der Waals forces, forming aligned CNT arrays [12]. Numerous parametric studies have been reported in the past few years and the carbon and catalyst feeding rates are widely accepted as the most influential 
factors on the resulting CNT properties [13-15]. However, the control of both carbon and catalytic feeding rates often requires the fine tuning of multiple parameters, such as the reaction temperatures, synthesis time, and nature and ratio of carbon and catalyst sources. For instance, the size of catalyst particles can be modulated by the catalyst precursor feeding rate via the ferrocene concentration in the feed solution or the evaporation temperature [16-18].

The control of both carbon and catalytic feeding rates may be achieved by the accurate regulation of hydrogen, which would open up a simple and versatile method for the selective synthesis of various types of CNTs. In addition, since hydrogen is almost always present in CVD processing systems, either directly as a feedstock or indirectly as a byproduct of the reaction, a thorough understanding of its role in the formation of carbon nanomaterials is critical. In conventional CVD systems, hydrogen is mainly used to reduce the oxidized catalyst particles as a pre-treatment step. However, very limited studies have reported the effect of hydrogen in FCCVD synthesis of CNTs, whereas its presence is known to have a strong influence on the decomposition kinetics of both catalytic and hydrocarbon species $[12,13]$. Previous works on the CVD growth of CNTs using pre-deposited catalysts showed that the CNT morphology and crystalline structure can be greatly influenced by hydrogen flow rates [19]. Some studies revealed synergistic effects between hydrogen and carbon precursor in the CNT growth process [20], while other reports indicated that hydrogen can etch pyrolytic carbon from the catalyst surface, thus prolonging the catalyst activity [21]. These observations motivate a detailed investigation of the role of hydrogen on the FCCVD synthesis of CNTs. In 
particular, the precise structural control of CNTs by the sole regulation of hydrogen has not been explored entirely and more efforts are required to determine whether there is a link between the gas chemistry and the CNT growth process [22].

In this paper, the influence of hydrogen on the properties of CNTs synthesized on quartz and alumina micro-particles $\left(\mu \mathrm{Al}_{2} \mathrm{O}_{3}\right)$ by FCCVD was investigated. The CNT growth was carried at $650{ }^{\circ} \mathrm{C}$ with the ratio of hydrogen to total gas ranging from 0 to 50 vol.\%. Lower synthesis temperature was achieved compared to other FCCVD systems (i.e. typically above $800{ }^{\circ} \mathrm{C}$ ), which could increase the growth lifetime and make the CNT synthesis more practical for various applications [23]. The evolutions in the gas phase composition during the CVD process was recorded in real time by mass spectrometry. The analysis of the decomposition species synthesized from reactant inputs was correlated with the CNT yield, length, diameter, wall number, and crystallinity to provide new insights into the role of hydrogen in the formation of CNTs by FCCVD.

\section{Experimental methods}

\subsection{Synthesis of carbon nanotubes}

Vertically aligned CNTs were synthesized under atmospheric pressure in a horizontal CVD reactor using a 1,200 $\mathrm{mm}$ long quartz tube with an inner diameter of $45 \mathrm{~mm}$ and argon as the reactor and carrier gas (Fig. 1a). The reactor was heated by a three-zone electrical furnace (CARBOLITE HZS) to $650^{\circ} \mathrm{C}$ under $1 \mathrm{~L} \mathrm{~min}^{-1}$ argon flow. 
The temperature profile along the heated zone is shown in Fig. 1b. Hydrogen was introduced and the system was stabilized for $15 \mathrm{~min}$. To eliminate possible side effects from impurities in the gas composition, high purity hydrogen (99.99\%) was utilized with levels of $\mathrm{O}_{2}$ and $\mathrm{H}_{2} \mathrm{O}$ as low as 0.1 and $0.5 \mathrm{ppm}$, respectively. The precursor solution consisted of a liquid feedstock of carbon source (i.e. ortho-xylene, 98.5\% Alfa Aesar) with dissolved ferrocene $\left(0.01 \mathrm{~g} \mathrm{~mL}^{-1}\right)$, which was injected into the reactor at a rate of $0.2 \mathrm{~mL} \mathrm{~min}{ }^{-1}$ using a syringe system fitted with a liquid flow meter (Razer Science, R99-E). Acetylene was also provided to the system at a rate of $0.02 \mathrm{~L} \mathrm{~min}^{-1}$ to serve as a second carbon precursor. The addition of acetylene in a gas/liquid carbon source mixture was found to accelerates the FCCVD synthesis of CNTs[24]. Digital mass flow meters (Bronkhorst, France) were used to control the gas flow such that the total flow rate was kept constant at $1 \mathrm{~L} \mathrm{~min}^{-1}$, as detailed in Table 1. After 10 min the injection of all carbon and catalytic sources was stopped and the reactor was cooled down to room temperature under argon and hydrogen atmospheres. CNTs were synthesized onto two different substrates: quartz plates and micro-spherical alumina particles $\left(\mu \mathrm{Al}_{2} \mathrm{O}_{3}\right.$, size ranging in 3-10 $\mu \mathrm{m}$, with $99.8 \%$ purity including $800 \mathrm{ppm} \mathrm{SiO}_{2}$, 600 ppm $\mathrm{Na}_{2} \mathrm{O}$, purchased from Performance Ceramic company, Peninsula, $\mathrm{OH}, \mathrm{USA}$ ). The $\mu \mathrm{Al}_{2} \mathrm{O}_{3}$ particles exhibited a multiphase crystallographic structure, containing mostly the thermodynamically stable hexagonal $\alpha-\mathrm{Al}_{2} \mathrm{O}_{3}$, and to a lesser extent metastable tetragonal $\delta$ and monoclinic $\theta$ phases. It is also worth noting that no evident phase-transformation occurred when the $\mu \mathrm{Al}_{2} \mathrm{O}_{3}$ particles were heated at temperatures up to $800^{\circ} \mathrm{C}$ [25]. The CNT growth was located at a fixed position in the middle of the 
heated zone $(20-30 \mathrm{~cm})$ where the temperature was constant, as depicted in Fig. $\mathbf{1 b}$.

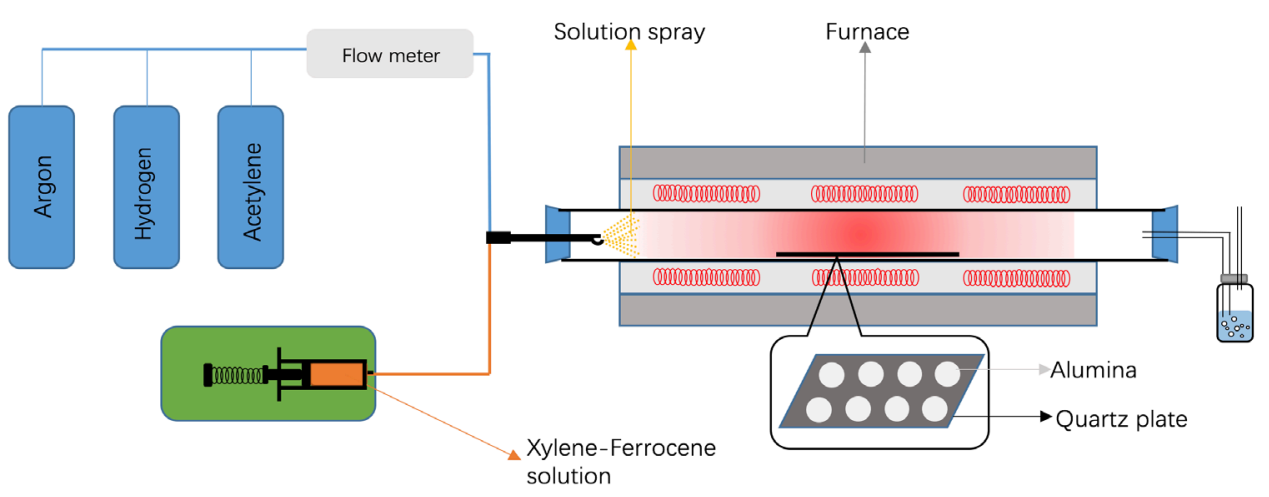

Fig. 1a Scheme of the FCCVD system

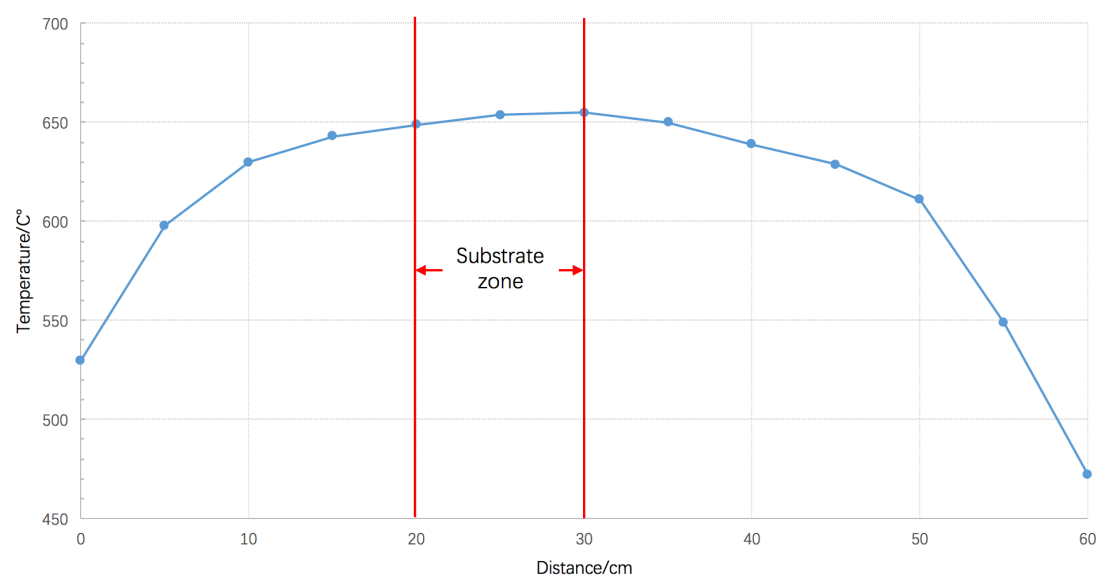

Fig. 1b Temperature profile along the heated zone $\left(650^{\circ} \mathrm{C}\right)$

Table 1. Summary of the different synthesis conditions. For each experiment, the 
reaction temperature, ferrocene concentration and liquid flow were set constant at $650^{\circ} \mathrm{C}, 0.01 \mathrm{~g} \mathrm{~mL}^{-1}$ and $0.2 \mathrm{~mL} \mathrm{~min}^{-1}$, respectively. ${ }^{*}$ No CNTs were observed under the corresponding conditions.

\begin{tabular}{|c|c|c|c|c|c|c|}
\hline Exp. & Support & $\begin{array}{c}\text { Ar flow } \\
(\mathbf{L} / \mathbf{m i n})\end{array}$ & $\begin{array}{c}\mathbf{H}_{2} \text { flow } \\
(\mathbf{L} / \mathbf{m i n})\end{array}$ & $\begin{array}{c}\mathbf{C}_{2} \mathbf{H}_{2} \text { flow } \\
(\mathbf{L} / \mathbf{m i n})\end{array}$ & $\begin{array}{c}\text { CNT length } \\
(\boldsymbol{\mu m})\end{array}$ & $\begin{array}{c}\text { CNT diameter } \\
(\mathbf{n m})\end{array}$ \\
\hline 1 & Quartz & 0.98 & 0 & 0.02 & $0.0^{*}$ & $0.0^{*}$ \\
\hline 2 & Quartz & 0.93 & 0.05 & 0.02 & 6.4 & 24.0 \\
\hline 3 & Quartz & 0.88 & 0.1 & 0.02 & 20.3 & 20.7 \\
\hline 4 & Quartz & 0.78 & 0.2 & 0.02 & 18.6 & 19.9 \\
\hline 5 & Quartz & 0.68 & 0.3 & 0.02 & 14.7 & 18.5 \\
\hline 6 & Quartz & 0.58 & 0.4 & 0.02 & 13.6 & 17.1 \\
\hline 7 & $\mathrm{Quartz}$ & 0.48 & 0.5 & 0.02 & 14.0 & 16.6 \\
\hline 8 & $\mu \mathrm{Al}_{2} \mathrm{O}_{3}$ & 0.98 & 0 & 0.02 & $0.0 *$ & $0.0 *$ \\
\hline 9 & $\mu \mathrm{Al}_{2} \mathrm{O}_{3}$ & 0.93 & 0.05 & 0.02 & 17.8 & 14.3 \\
\hline 10 & $\mu \mathrm{Al}_{2} \mathrm{O}_{3}$ & 0.88 & 0.1 & 0.02 & 33.4 & 14.4 \\
\hline 11 & $\mu \mathrm{Al}_{2} \mathrm{O}_{3}$ & 0.78 & 0.2 & 0.02 & 29.1 & 13.2 \\
\hline 12 & $\mu \mathrm{Al}_{2} \mathrm{O}_{3}$ & 0.68 & 0.3 & 0.02 & 26.5 & 12.1 \\
\hline 13 & $\mu \mathrm{Al}_{2} \mathrm{O}_{3}$ & 0.58 & 0.4 & 0.02 & 26.0 & 11.5 \\
\hline 14 & $\mu \mathrm{Al}_{2} \mathrm{O}_{3}$ & 0.48 & 0.5 & 0.02 & 24.4 & 11.4 \\
\hline
\end{tabular}

\subsection{Characterization}

The evolution in the gas phase composition during the CVD process was recorded in real time by mass spectrometry (MS, Pfeiffer Vacuum Thermostar GSD 301 T3). The gas exhaust at the end of the heated zone $(40 \mathrm{~cm})$ was probed using a metallic stainless steel capillary of $0.3 \mathrm{~mm}$ diameter. Thermogravimetric analyses (TGA) were conducted in air on a Netzsch analyzer (STA 449 F3 Jupiter) using a thermo-program between 50 and $900{ }^{\circ} \mathrm{C}$ at a heating rate of $10{ }^{\circ} \mathrm{C} / \mathrm{min}$. The oxidation temperatures for the as- 
synthesized CNTs were in the range of $400-650^{\circ} \mathrm{C}$, while the weight loss at $350^{\circ} \mathrm{C}$ was associated to the non-crystalline carbonaceous structures and used to estimate the amount of amorphous carbon[26]. Raman spectra were recorded over the range of 1000-2000 $\mathrm{cm}^{-1}$ with a spectral resolution of $1 \mathrm{~cm}^{-1}$ by a LabRAM Horiba Raman spectrometer using the $632.8 \mathrm{~nm}$ emission of a He-Ne laser source. Samples were analyzed by registering the spectra for each specimen randomly on three different positions. All recorded curves were baseline and fitted using Lorentzian line shapes, and the D- and G-peak intensities were used for the calculation of the IG/ID ratios. Electron microscopy observations were used to investigate the morphology of the asprepared materials. Transmission electron microscopy (TEM) was performed using a FEI Titan instrument equipped with an aberration-corrected condenser operating at 200 $\mathrm{kV}$, and scanning electron microscopy (SEM) was conducted on a ZEISS LEO 1530 Gemini FEG instrument with an accelerating voltage of $5 \mathrm{kV}$. A thorough statistical analysis of over 50 tubes (from SEM and TEM micrographs) was conducted for each synthesis condition. The results were subjected to one-way analysis of variance (ANOVA) followed by Tukey tests to ensure statistical significance. CNT length and diameter were analyzed based on $5 \%$ alpha level (i.e. 95\% confidence). Statistical differences in CNT length and diameter were determined with p-values $<0.05$.

\section{Results and discussion}

\subsection{Influence of hydrogen on the decomposition of reactant inputs}

The decomposition species from reactant inputs was recorded by in situ mass 
spectrometry for different hydrogen flow rates. As shown in Fig. 2a, a fast decline in total hydrocarbon concentration with increasing hydrogen flow is first observed. The ion intensities representing the amounts of xylene and acetylene respectively decrease by $45 \%$ and $36 \%$ at $0.1 \mathrm{~L} \mathrm{~min}^{-1}$ hydrogen when compared to hydrogen-free synthesis. The reduction of all hydrocarbon quantities in the gas phase can be attributed to the conversion of hydrocarbon vapors into solid carbon structures. It should be noted that the nature of the substrate does not influence the decomposition of the reactant inputs, as no significant differences in the gas phase composition have been observed when either quartz or $\mu \mathrm{Al}_{2} \mathrm{O}_{3}$ were used as substrate. From the point of view of reaction kinetics, relatively high hydrogen content facilitates and increases the carbon deposition rate [13], leading to increased solid carbon yield, as illustrated by the significant mass loss in the TGA profiles of CNTs when the hydrogen flow increases from 0.05 to $0.3 \mathrm{~L} \mathrm{~min}^{-1}$ (inset Fig. 2b). However, our observations at higher hydrogen flows contradict this principle and the mass of deposited carbon is reduced when the hydrogen content increases further (inset Fig. 2b). Above $0.1 \mathrm{~L} \mathrm{~min}^{-1}$ hydrogen, the quantities of all species in the gas phase increase, with $44 \%$ and $33 \%$ ion intensity augmentation for xylene and acetylene from 0.1 to $0.5 \mathrm{~L} \mathrm{~min}^{-1}$ hydrogen, respectively. This indicates that within this hydrogen flow range, the hydrocarbon decomposition rate exceeds the rate of carbon deposition. Under such conditions, hydrocarbon pyrolysis is promoted which leads to copious amorphous carbon consisting predominantly of polycyclic aromatic hydrocarbons, as observed in the SEM inset in Fig. 2b [27]. Moreover, in Fig. 2b the mass of amorphous carbon normalized to the 
total mass of carbon nearly doubled when the hydrogen flow increases from 0.1 to 0.2 $\mathrm{L} \min ^{-1}$. However, when the hydrogen content was increased further, the quantity of amorphous carbon was drastically reduced. Noteworthy, above $0.3 \mathrm{~L} \mathrm{~min}^{-1}$ hydrogen, the amount of acetylene reaches a quasi-steady state and the quantity of methane increases significantly. The abrupt drop of amorphous carbon is correlated with the large amount of methane in the reactor atmosphere, as shown in Fig. 2. Previous studies have found that methane is the dominant product from the etching process of carbons when hydrogen is involved [28], thus indicating that high hydrogen content can induce the gasification of carbon. In summary, with a small amount of hydrogen, hydrogen can increase the deposition rate, including large quantities of amorphous carbon. However, the etching effect is promoted with the augmentation of hydrogen content and the carbon deposition rate is reduced. Therefore, the effects of hydrogen on carbon deposition can be both accelerating and inhibiting depending on the experimental conditions. Noteworthy, the hydrogen contribution is not only influenced by the ratio at which it is introduced in the system (i.e. hydrogen:total gas ratio) but also by the reaction temperature. Figure $2 \mathbf{c}$ shows the evolution of methane content in the gas phase at different temperatures (i.e. $550,650,700,850^{\circ} \mathrm{C}$ ) and for varying hydrogen flows (i.e. $0,0.1$, and $0.3 \mathrm{~L} \mathrm{~min}^{-1}$ ). At $650^{\circ} \mathrm{C}$ and below, the evolution of methane content follows the same trend as previously described with a decrease at low hydrogen flow (i.e. $0.1 \mathrm{~L} \mathrm{~min}^{-1}$ ) and an increase at high hydrogen flow (i.e. $0.3 \mathrm{~L} \mathrm{~min}^{-1}$ ). For temperatures higher than $700^{\circ} \mathrm{C}$, the quantity of methane increases with the augmentation of hydrogen over the full range of flow rates studied. Since the quantity 
of methane in the reacting atmosphere can be correlated to some degree to the hydrogen etching effect [28], it can be observed that the inhibiting role of hydrogen in the carbon deposition process is promoted at higher temperatures (i.e. above $700^{\circ} \mathrm{C}$ ) regardless of the hydrogen flow. Furthermore, the growth was found to shift from nanotubes to nanofibers beyond $900^{\circ} \mathrm{C}$ at relatively high hydrogen content [29].

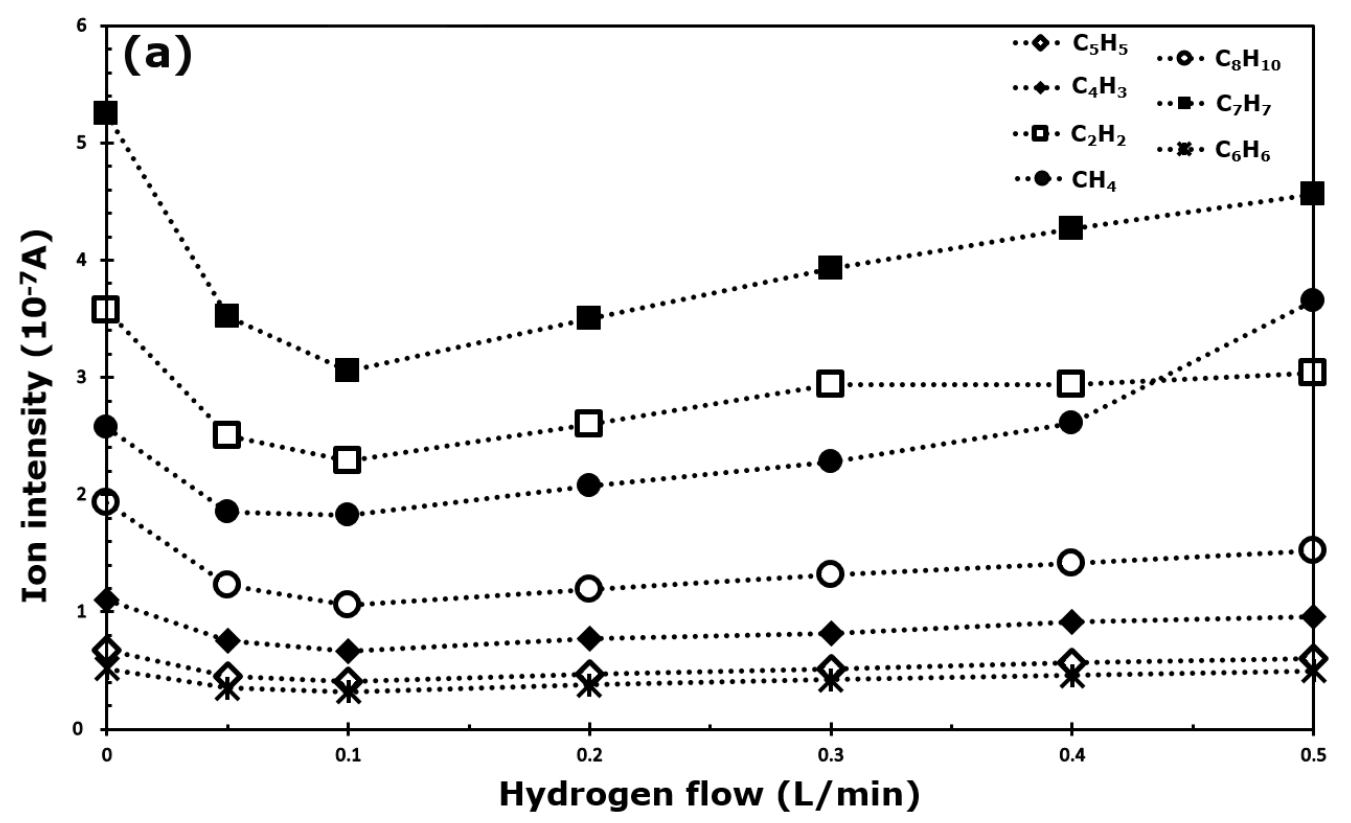

Fig. 2a. Evolution of the ion intensity of the main hydrocarbons present in the gas phase measured by in situ mass spectrometry as a function of hydrogen flow rate. 


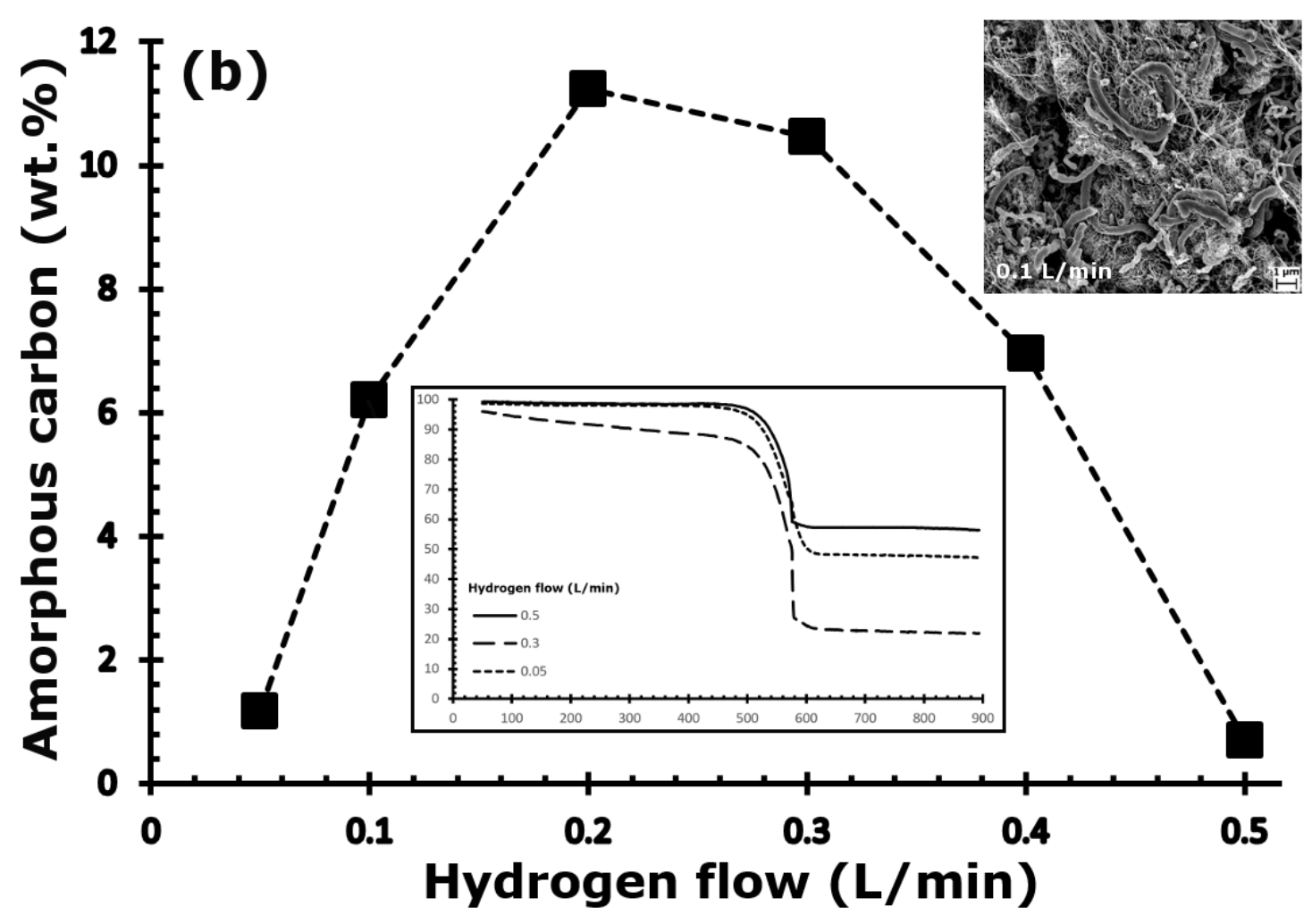

Fig. 2b. Mass of amorphous carbon normalized to the total mass of carbon as a function of hydrogen flow rate. The inset represents the TGA profiles of CNTs synthesized on $\mu \mathrm{Al}_{2} \mathrm{O}_{3}$ at 0.05 (dotted line), 0.3 (dashed line), and 0.5 (straight line) $\mathrm{L} / \mathrm{min}$ hydrogen.

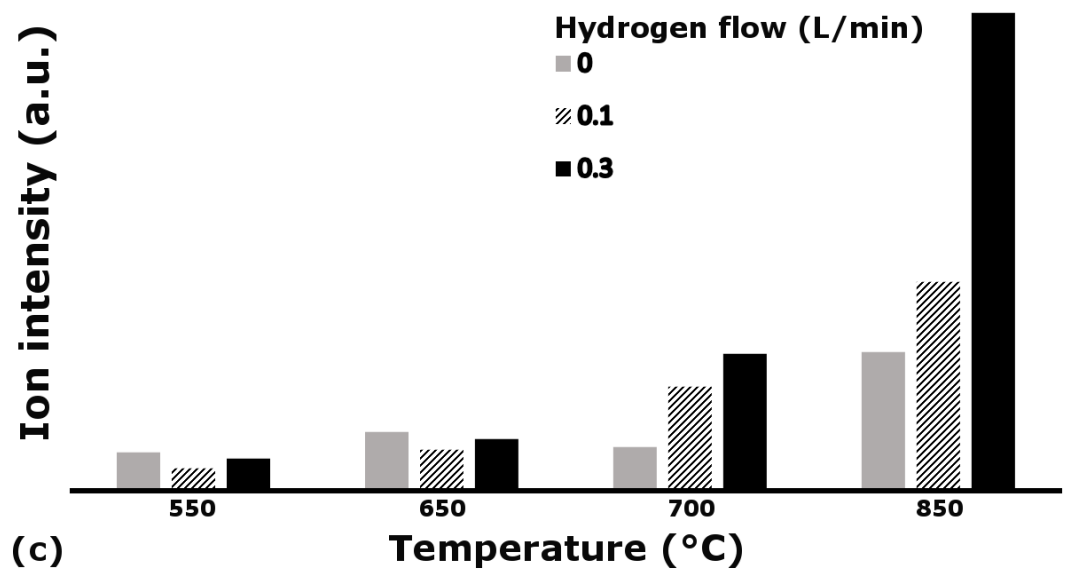

Fig. 2c. Evolution of the quantity of methane in the reacting atmosphere at different temperatures (i.e. $550,650,700,850^{\circ} \mathrm{C}$ ) and for varying hydrogen flows (i.e. 0, 0.1, and $0.3 \mathrm{~L} \mathrm{~min}^{-1}$ ). 


\subsection{Influence of hydrogen on the product nature}

CNTs have been successfully synthesized in all cases when hydrogen was introduced in the reactor. Only pyrolytic carbon was found when hydrogen was not provided in the gas mixture, which is consistent with other reports $[30,31]$. When no hydrogen is provided in the system, higher temperatures are required to achieve sufficient hydrocarbon decomposition and catalytic activity for CNT synthesis [32]. In such case, hydrocarbon with high number of hydrogen atoms per carbon atom are critical to promote the growth of CNTs [30]. Without the presence of hydrogen in the reacting atmosphere, hydrocarbons have to chemisorb on the catalyst surface, since the formation of $\mathrm{CHx}$ in the gas phase is thermodynamically not favorable under the considered synthesis conditions. As the hydrocarbon molecules decompose and leave the catalyst surface covered with partially dehydrogenated fragments, polymeric carbon chains are formed, ultimately resulting in graphitic structures. However, it has been demonstrated that there exists a certain barrier during the dissociative chemisorption of hydrocarbon on catalyst surface. For example, the first step of acetylene catalytic decomposition on iron particles with formation of chemisorbed $(\mathrm{CH})$ s radicals should overcome a $1.25 \mathrm{eV}\left(\sim 16 \mathrm{kT}\right.$ at $\left.650{ }^{\circ} \mathrm{C}\right)$ activation barrier [33]. Since CNT growth was only observed when hydrogen was introduced in the reactor, it seems reasonable to assume that hydrogen helps overcome this barrier and thus acts as a catalyst for the production of CNTs. It has been proposed that molecular hydrogen dissociates on catalyst surface and forms active hydrogen atoms [31]. These hydrogen atoms may promote the activation of physisorbed hydrocarbons, resulting in the formation of 
surface bound $(\mathrm{CHx}) \mathrm{s}$ radical, which eventually leads to the growth of graphitic structures through the agglomeration of $(\mathrm{CHx}) \mathrm{s}$ into multimeric $(\mathrm{CnHy})$. This is consistent with previous research reporting that the formation of a graphitic network at the early stage of the CNT growth occurs through the intermediate formation of partially dehydrogenated graphitic islands [34].

\subsection{Influence of substrate on the CNT morphology}

Vertically-aligned CNTs were successfully grown on both quartz and $\mu \mathrm{Al}_{2} \mathrm{O}_{3}$ substrates. SEM observations revealed that CNTs are aligned perpendicularly to the substrates forming carpets on quartz and multi-branched structures on $\mu \mathrm{Al}_{2} \mathrm{O}_{3}$, which is consistent with CNT arrangements commonly obtained through FCCVD on similar substrates [13]. Figure 3 shows that CNTs synthesized on $\mu \mathrm{Al}_{2} \mathrm{O}_{3}$ exhibit smaller mean diameters and are nearly twice as long as their counterparts grown on quartz. Since no differences in the gas phase composition were observed when either quartz or $\mu \mathrm{Al}_{2} \mathrm{O}_{3}$ were used as substrate, it is reasonable to assume identical carbon supply rates in each case under similar conditions. The difference in CNT morphology between quartz and $\mu \mathrm{Al}_{2} \mathrm{O}_{3}$ may thus be attributed to variations in the catalyst particle size between each substrate. Catalyst-support interfacial reactions play critical role on the formation of catalyst particles and their ability to dissolve carbon in seeding the nucleation and growth of CNTs. It was found that $\mu \mathrm{Al}_{2} \mathrm{O}_{3}$ restricts $\mathrm{Fe}$ surface mobility, resulting in a narrow catalyst particle size distribution as compared to quartz [35]. This is illustrated by the larger distributions of CNT wall number and inner diameter on quartz than on 
$\mu \mathrm{Al}_{2} \mathrm{O}_{3}$ in Fig. 4 \& 5. Large particle size distribution induces coarsening through Otswald ripening, which can reduce the catalytic activity, hence leading to larger CNT diameters and lower growth rates [36]. Although substituting conventional flat substrates for beads with larger available growth surface can be a productive strategy for the large scale synthesis of CNTs $[37,38]$, the masses of carbon products collected after the FCCVD synthesis at $0.05 \mathrm{~L} \mathrm{~min}^{-1}$ were similar for each substrate, with $74 \mathrm{mg}$ on quartz and $71 \mathrm{mg}$ on $\mu \mathrm{Al}_{2} \mathrm{O}_{3}$. The corresponding carbon yield was close to $40 \%$, which is similar to values reported in other studies at higher temperatures [39]. Moreover, the carbon yield obtained by TGA showed a good correlation with the CNT abundance observed in the electron microscope images and the Raman spectra. At 0.05 $\mathrm{L} \mathrm{min}^{-1}$ hydrogen, the major products were CNTs with very small amount of amorphous carbon. Therefore, we can assume that the CNT yield is closely related to the carbon yield in this case.
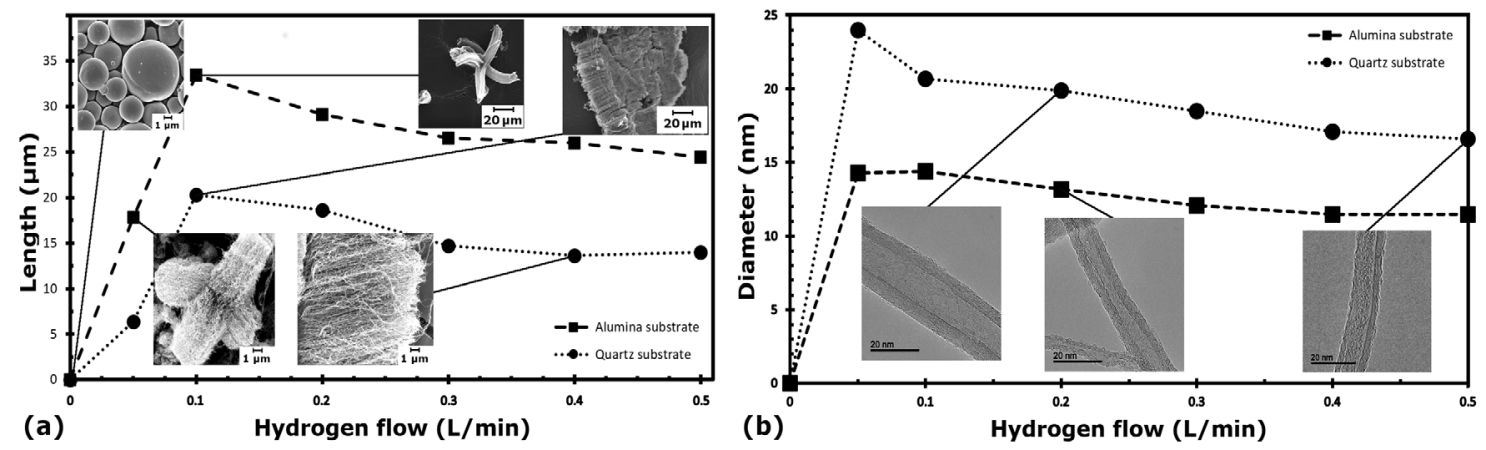

Fig. 3. Plots of CNT length (a) and mean diameter (b) as a function of hydrogen flow.

\subsection{Influence of hydrogen on the CNT morphology}


As observed in Fig. 3, the evolution of CNT morphology as a function of hydrogen flow is similar on both substrates. In each case, the CNT length (Fig. 3a) and diameter (Fig. 3b) increase rapidly with the hydrogen flow and reach their maximum at 0.1 and $0.05 \mathrm{~L} / \mathrm{min}$, respectively, before decreasing as the hydrogen flow increases further. Below $0.1 \mathrm{~L} / \mathrm{min}$, increase in hydrogen flow directly translates to higher CNT growth rate, suggesting that carbon supply might be the rate limiting step of the reaction. CNT growth proceeds through several elementary processes, including decomposition of carbonaceous gases on the catalyst particles (carbon supply), diffusion of carbon atoms through/over the catalyst particles (carbon diffusion), and precipitation of carbon atoms as CNTs from the catalyst particles (CNT growth) [7]. The role played by hydrogen in the augmentation of carbon supply is twofold. On one hand, hydrogen promotes the decomposition of hydrocarbon vapors into more reactive byproducts [13]. On the other hand, hydrogen may also serve as an activation agent for the dissociation of physisorbed hydrocarbons on the surface of catalyst particles, as described above. 

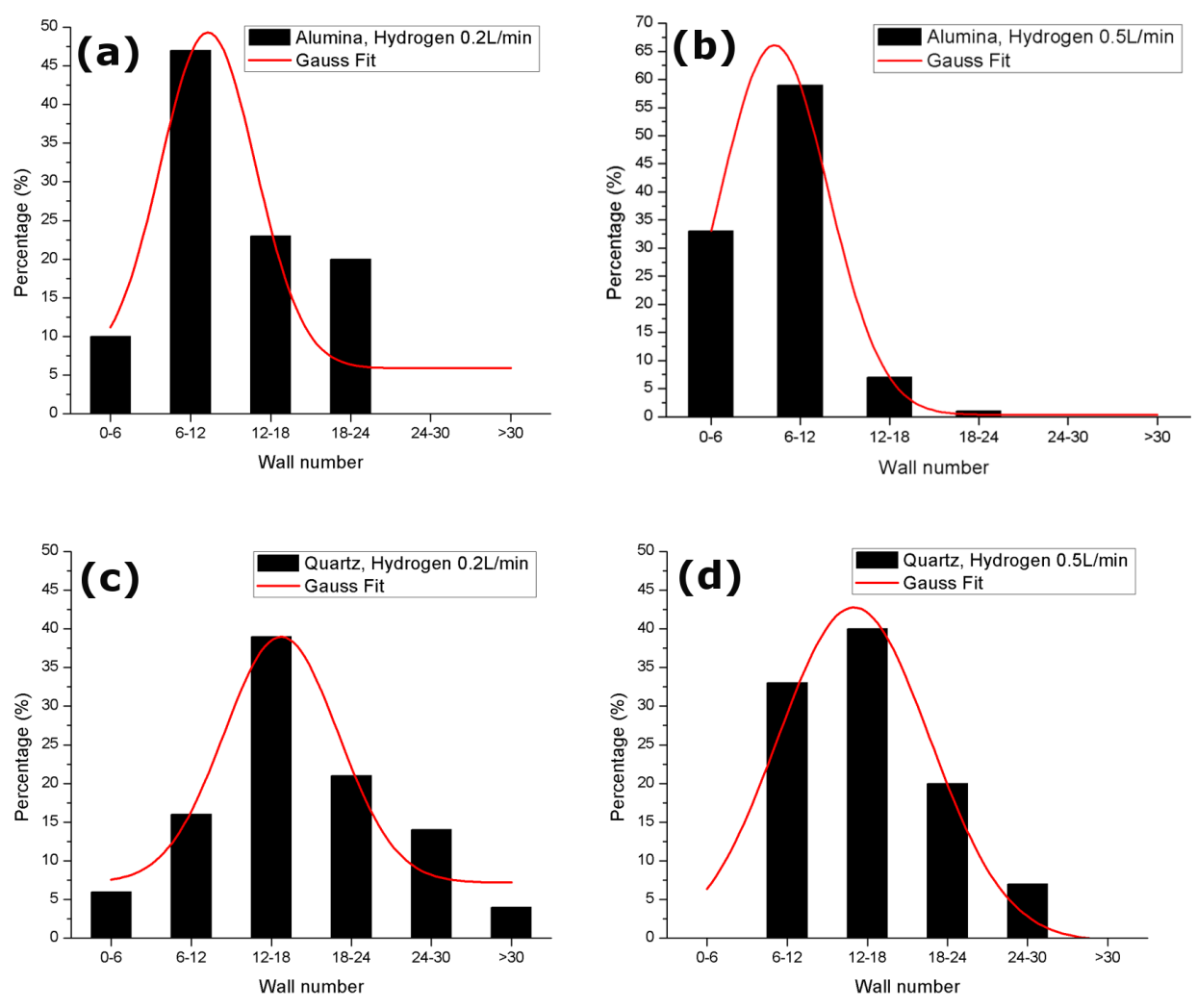

Fig. 4. Wall number distribution histograms of CNTs synthesized by (a,c) $0.2 \mathrm{~L} / \mathrm{min}$ and $(b, d) 0.5 \mathrm{~L} / \mathrm{min}$ hydrogen on $(\mathrm{a}, \mathrm{b}) \mu \mathrm{Al}_{2} \mathrm{O}_{3}$ and $(\mathrm{c}, \mathrm{d})$ quartz.

At higher hydrogen flows (i.e. above $0.1 \mathrm{~L} / \mathrm{min}$ ), carbon supply will occur more quickly than the subsequent processes (i.e. carbon diffusion and CNT growth), and carbon atoms will accumulate on the catalyst surface forming carbon byproducts, as described by the rapid augmentation of amorphous carbon with the hydrogen content (Fig. 2b). Although the presence of these carbon byproducts does not prevent catalytic hydrocarbon decomposition and graphitization processes, it reduces the CNT growth rate, as previously reported [27]. Furthermore, the decrease in CNT length and diameter within this hydrogen flow range may also be attributed to catalytic hydrogenation, a process in which carbon in contact with the catalyst surface reacts with $\mathrm{H}_{2}$ to form $\mathrm{CH}_{4}$ 
[27]. The catalytic hydrogenation process was recently found to be dependent on the nature of the catalyst [30]. Hydrogen etched CNTs catalyzed by nickel, while it had no impact on the CNTs grown from cobalt. It is suggested that the activation energy for the sequential formation of multiple $\mathrm{C}-\mathrm{H}$ bonds at the metal-CNT interface is lower for $\mathrm{Ni}$ and $\mathrm{Fe}$ than for Co. Consequently, there is a competition between the precipitation of carbon from catalyst particles forming CNTs and the catalytic hydrogenation process at high hydrogen contents.
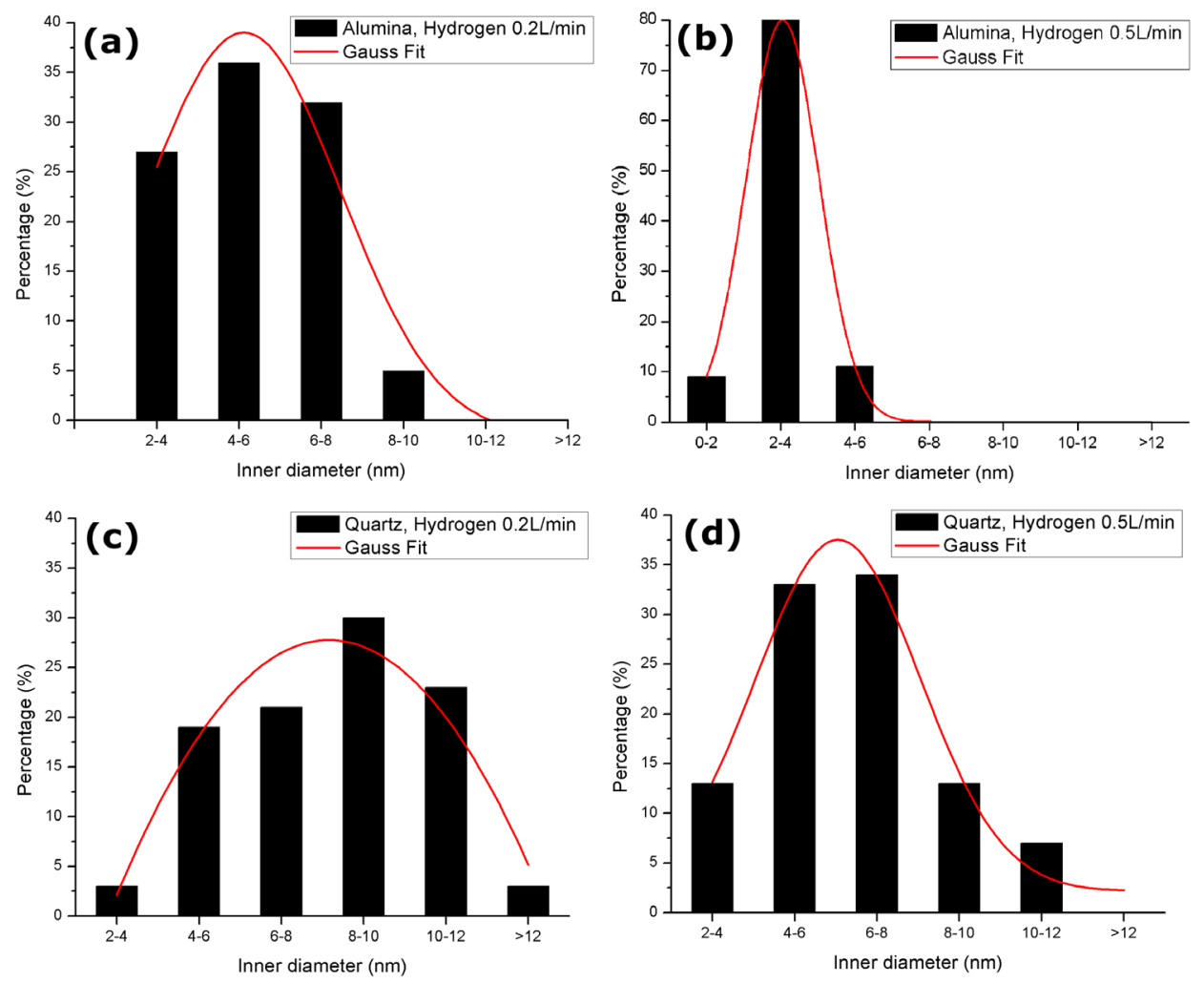

Fig. 5. Core diameter distribution histograms of CNTs synthesized by (a,c) $0.2 \mathrm{~L} / \mathrm{min}$ and (b,d) $0.5 \mathrm{~L} / \mathrm{min}$ hydrogen on $(\mathrm{a}, \mathrm{b}) \mu \mathrm{Al}_{2} \mathrm{O}_{3}$ and $(\mathrm{c}, \mathrm{d})$ quartz.

To provide greater insight about the influence of hydrogen flow on the CNT 
diameter, the distribution of CNT wall number and core tube diameter was examined at different hydrogen flows, as depicted in Fig. 4 \& 5. For quartz and $\mu \mathrm{Al}_{2} \mathrm{O}_{3}$, all changes in the CNT wall number distributions as a function of hydrogen flow are rather small compared to those in the CNT inner diameter distribution. There is no or little variation in the wall numbers of CNTs prepared on both substrates as a function of hydrogen flow (i.e. 6-30 walls on quartz, and 6-24 walls on $\mu \mathrm{Al}_{2} \mathrm{O}_{3}$ ), and the Gaussian bell-shaped curves used to fit the data remain nearly identical when the hydrogen flow increases from 0.2 to $0.5 \mathrm{~L} / \mathrm{min}$ (Fig. 4). However, the Gaussian fits of the core tube distribution grown on both substrates are shifted toward lower diameters when the hydrogen flow rate is more than doubled (Fig. 5). Moreover, the CNT inner diameter distributions are narrower at high hydrogen flow rate. The Full Width at Half Maximum (FWHM) of the Gaussian fits of the core tube distributions for CNTs prepared on quartz by 0.2 and $0.5 \mathrm{~L} / \mathrm{min}$ are 7 and $4 \mathrm{~nm}$, respectively. Similarly, the FWHM of the corresponding Gaussian bell-shaped curves of the inner diameter distributions for CNTs prepared on $\mu \mathrm{Al}_{2} \mathrm{O}_{3}$ by 0.2 and $0.5 \mathrm{~L} / \mathrm{min}$ are 5 and $2 \mathrm{~nm}$, respectively. These observations are in contradiction with previous results where hydrogen was found to have a pronounced effect on the wall number of CNTs [19]. In this report, a predeposited catalyst CVD process was used and yielded CNTs with smaller diameter, including single-wall and double-wall CNTs. According to the statistical analysis of Chiodarelli et al. [40], when the average outer diameter increases, the inner diameter is no longer solely related to the outer diameter, but is also influenced by CVD parameters. In particular, it was found that the inner diameter is modified by the instantaneous 
carbon concentration of the catalyst particle, which depends on both carbon supply and consumption [41]. As abovementioned, hydrogen likely influences the carbon supply in both deposited and floating CCVD systems. Hence, the variations between these two researches may arise from different mechanism involved in the formation of catalyst particles. In the present work, the decomposition of ferrocene leads to the in situ nucleation of catalyst particles. Since ferrocene decomposition is significantly influenced by the presence of hydrogen in the reacting atmosphere [13, 42], it is reasonable to assume that hydrogen plays a role in the formation of catalyst particles, thus indirectly influencing the carbon consumption. While ferrocene spontaneously decomposes at temperature higher than $500{ }^{\circ} \mathrm{C}$ [43], the rate of decomposition is reduced in a hydrogen environment. Since the first step in ferrocene decomposition is the breaking of a C-H bond with the production of hydrogen $[44,45]$, the presence of high hydrogen content in the reactor would suppress the rate of ferrocene decomposition, hence resulting in lower catalyst particle size and availability. To validate this claim, further work is required to investigate the effect of hydrogen on the catalyst nanoparticle growth dynamics.

Therefore, hydrogen plays a dual role during the FCCVD process by both promoting and hindering CNT growth through various phenomena. Balancing these different effects is critical to improve the synthesis selectivity and can be achieved by the accurate control of the hydrogen flow. Similar observations were recently reported during the plasma-assisted CVD synthesis of CNTs, however, different growth conditions were employed where both $\mathrm{H}$ atoms and $\mathrm{H}_{2}$ coexist in the plasma mixture, 
with molecular $\mathrm{H}_{2}$ being less reactive than $\mathrm{H}$ atoms [30].

\subsection{Influence of hydrogen on the CNT crystallinity}

Representative Raman profiles of the as-grown CNTs are presented in insets of Fig. 6. All specimens display strong peaks near 1336 and $1590 \mathrm{~cm}^{-1}$, assigned to the D- and G-bands, respectively. The G band is the characteristic peak for the stretching vibration of carbon sp2 bonds in a hexagonal lattice, and the $\mathrm{D}$ band corresponds to the disordered sp2 phase plus possible contributions of the scattering of sp3-bonded carbon [46]. The integrated intensity ratio of the $\mathrm{G}$ band to the $\mathrm{D}$ band (IG/ID) is commonly invoked as a benchmark of the CNT crystallinity. Figure 6 is a plot of the IG/ID ratio of the CNTs as a function of hydrogen flow rate. In all cases, the IG/ID ratio is smaller than 1 and the relatively low-quality nature of CNTs can be identified from the zoomed-in TEM images (insets Fig. 3b) as their rough surfaces. The presence of defects along the walls and at the ends of the nanotubes is consistent with the relatively low thermal stability of CNTs observed by TGA (inset Fig. 2b), which can also be attributed to the enhanced oxidation of CNTs due to the presence of catalyst.

The hydrogen flow exhibits a pronounced effect on the CNT crystallinity. The IG/ID ratio first increases with higher hydrogen flow rates up to $0.1 \mathrm{~L} \mathrm{~min}^{-1}$, where CNTs with the best structural integrity are observed. Comparing Fig. 3a with Fig. 6, it can be found that longer CNTs tend to present higher crystalline quality, which is consistent with other studies [19]. For hydrogen flow rates ranging from 0.1 to $0.5 \mathrm{~L}$ $\min ^{-1}$, the defect site surface density of CNTs increases with the hydrogen content, with 
the IG/ID passing from 0.91 to 0.70 . In particular, the IG/ID ratio remains close to 1 until the hydrogen flow rate reaches values equal or above $0.2 \mathrm{~L} \mathrm{~min}^{-1}$ where the CNT crystalline quality drastically diminishes. The potential contribution of pyrolytic carbonaceous impurities to the D-band at higher hydrogen content is unlikely considering the significant reduction of amorphous carbon observed within this hydrogen flow range, as seen in Fig. $2 \mathbf{b}$.

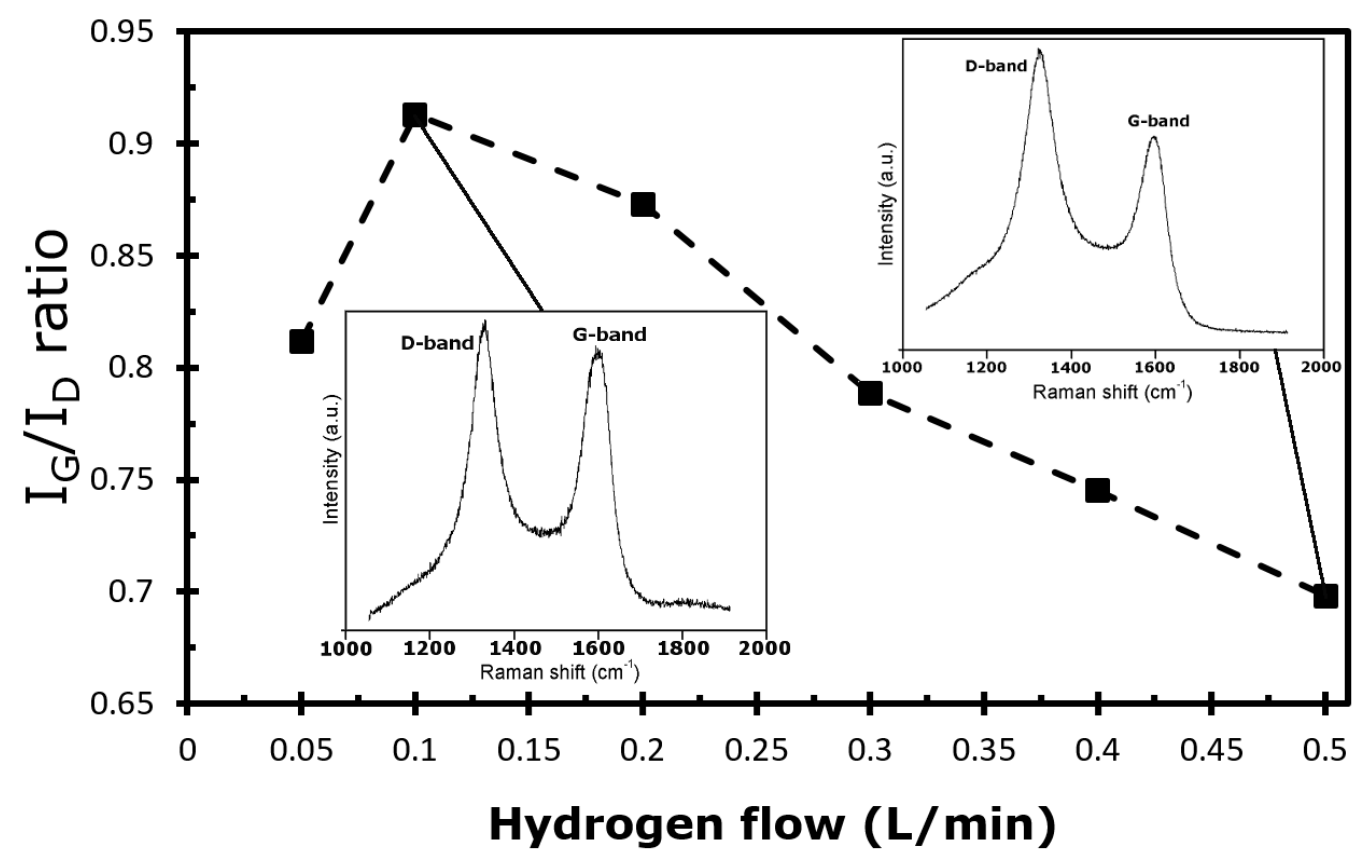

Fig. 6. Plot of the IG/ID ratio of CNTs grown on $\mu \mathrm{Al}_{2} \mathrm{O}_{3}$ as a function of hydrogen flow. Representative Raman spectra are shown in insets.

During the FCCVD process, many unreacted compounds remain and attach to the CNT surface. It is known that $\mathrm{H}$ atoms can etch carbonaceous materials $[47,48]$, and it seems reasonable to assume that hydrogen serves a similar role for the desorption of carbon species during the CNT growth process. At relatively low flow rates (below 0.1), 
hydrogen can help etching these materials, hence increasing the IG/ID ratio. However, these impurities deposited on the CNT surface along with defects on CNT walls may also act as the activation centers for the hydrogen etching effect, as observed in the formation of holes in graphene [31]. At higher flow rates, hydrogen can adsorb on these activated sites, non-uniformly distributed across the CNT length, in a similar way as reported in hydrogen storage studies [49]. The adsorption of hydrogen results in the occurrence of structural transformations in the continuous cylindrical graphene walls of nanotubes, as shown by the augmentation of the D-band in the Raman spectra at high hydrogen content (insets Fig. 6). These observations are consistent with recent reports about the surface modification of graphene and CNTs by annealing in hydrogen atmosphere $[50,51]$.

\section{Conclusion}

In summary, we have demonstrated the efficiency of the sole regulation of hydrogen flow for controlling the products nature and morphology during the FCCVD synthesis of CNTs. Vertically-aligned CNTs were successfully grown on different substrates and the CNT aspect ratio and crystallinity were adjusted through variations in hydrogen flow. The relative hydrogen content plays an important role in both gas chemistry and CNT growth mechanism. Hydrogen was found to promote hydrocarbon dissociation and decrease the decomposition rate of ferrocene, while leading to carbon gasification with formation of methane at high flow rates. Hydrogen may also act as catalyst in the dissociative sorption of hydrocarbons onto the surface of metal nanoparticles, thus 
facilitating the production of CNTs at lower temperatures. High hydrogen contents also induced the catalytic hydrogenation of carbon and resulted in surface modification in the continuous cylindrical graphene walls of nanotubes. Therefore, to achieve selective CNT synthesis at low temperatures, the right amount of hydrogen required to balance these different effects. We expect that these findings will guide future optimization of carbon nanomaterial synthesis and contribute to better control over the properties of CNTs prepared from FCCVD.

\section{Acknowledgements}

Y. Ma gratefully acknowledges the support of a Ph.D. stipend from the Chinese Scholarship Council (CSC). The authors thank Y. Liu and P. Haghi-Ashtiani for their assistance with electron microscopy observations.

\section{References}

1. Dichiara AB, Yuan J, Yao S, Sylvestre A, Zimmer L, Bai J. Effective synergistic effect of $\mathrm{Al}_{2} \mathrm{O}_{3}$ and SiC microparticles on the growth of carbon nanotubes and their application in high dielectric permittivity polymer composites. Journal of Materials Chemistry A, 2014. 2(21): p. 7980-7987.

2. Zhang Q, Huang JQ, Qian WZ, Zhang YY, Wei F. The road for nanomaterials industry: a review of carbon nanotube production, post-treatment, and bulk applications for composites and energy storage. Small, 2013. 9(8): p. 123765.

3. Dichiara AB, SF Harlander, RE Rogers. Fixed bed adsorption of diquat dibromide from aqueous solution using carbon nanotubes. RSC Advances, 2015. 5(76): p. 61508-61512.

4. Ihsanullah, Abbas A, Al-Amer AM, Laoui T, Al-Marri MJ, Nasser MS et al. 
Heavy metal removal from aqueous solution by advanced carbon nanotubes: Critical review of adsorption applications. Separation and Purification Technology, 2016. 157: p. 141-161.

5. Li W, Dichiara AB, Bai J. Carbon nanotube-graphene nanoplatelet hybrids as high-performance multifunctional reinforcements in epoxy composites. Composites Science and Technology, 2013. 74: p. 221-227.

6. Mittal G, Dhand V, Rhee KY, Park SJ, Lee WR. A review on carbon nanotubes and graphene as fillers in reinforced polymer nanocomposites. Journal of Industrial and Engineering Chemistry, 2015. 21: p. 11-25.

7. Jourdain V, Bichara C. Current understanding of the growth of carbon nanotubes in catalytic chemical vapour deposition. Carbon, 2013. 58: p. 239.

8. Rao CNR and Sen $\mathrm{R}$, Large aligned-nanotube bundles from ferrocene pyrolysis. Chem. Commun., 1998(15): p. 1525-1526.

9. Hou G, Su R, Wang A, Ng V, Li W, Song Y et al. The effect of a convection vortex on sock formation in the floating catalyst method for carbon nanotube synthesis. Carbon, 2016. 102: p.513-519

10. Mikhalchan A, Fan Z, Tran TQ Liu P, Tan V BC, Tay TE et al. Continuous and scalable fabrication and multifunctional properties of carbon nanotube aerogels from the floating catalyst method. Carbon, 2016. 102: p.409-418.

11. Barreiro A, Hampel S, Rümmeli MH, Kramberger C, Grüneis A, Biedermann $\mathrm{K}$ et al. Thermal decomposition of ferrocene as a method for production of single-walled carbon nanotubes without additional carbon sources. The Journal of Physical Chemistry B, 2006. 110(42): p. 20973-20977.

12. He D, Bozlar M, Genestoux M, Bai J. Diameter-and length-dependent selforganizations of multi-walled carbon nanotubes on spherical alumina microparticles. Carbon, 2010. 48(4): p. 1159-1170.

13. Dichiara $\mathrm{AB}, \mathrm{Bai}$ J. The growth of carbon nanotube multilayers on ceramic $\mu$-particles by catalytic chemical vapour deposition. Diamond and Related Materials, 2012. 29: p. 52-58.

14. Abbaslou RMM, Soltan J, Dalai AK. Effects of nanotubes pore size on the catalytic performances of iron catalysts supported on carbon nanotubes for Fischer-Tropsch synthesis. Applied Catalysis A: General, 2010. 379(1): p. 
129-134.

15. Harris JD, Raffaelle RP, Gennett T, Landi BJ, Hepp AF. Growth of multi-walled carbon nanotubes by injection CVD using cyclopentadienyliron dicarbonyl dimer and cyclooctatetraene iron tricarbonyl. Materials Science and Engineering: B, 2005. 116(3): p. 369-374.

16. Bai S, Li F, Yang QH, Cheng HM, Bai J. Influence of ferrocene/benzene mole ratio on the synthesis of carbon nanostructures. Chemical Physics Letters, 2003. 376(1-2): p. 83-89.

17. Yang X, Yuan L, Peterson VK, Minett AI, Yin Y, Harris, AT. Facile preparation of free-standing carbon nanotube arrays produced using two-step floatingferrocene chemical vapor deposition. ACS applied materials \& interfaces, 2012. 4(3): p. 1417-1422.

18. Yamada T, Namai T, Hata K, Futaba DN, Mizuno K, Fan J et al., Size-selective growth of double-walled carbon nanotube forests from engineered iron catalysts. Nature nanotechnology, 2006. 1(2): p. 131-136.

19. Zhang H, Cao G, Wang Z, Yang Y, Shi Z, Gu Z. Influence of ethylene and hydrogen flow rates on the wall number, crystallinity, and length of millimeter-long carbon nanotube array. The Journal of Physical Chemistry C, 2008. 112(33): p. 12706-12709.

20. Guellati O, Janowska I, Bégin D, Guerioune M, Mekhalif Z, Delhalle J et al. Influence of ethanol in the presence of $\mathrm{H} 2$ on the catalytic growth of vertically aligned carbon nanotubes. Appl. Catal. A, 2012. 423: p.7-14.

21. Wasel W, Kuwana K, Reilly P TA, Saito K. Experimental characterization of the role of hydrogen in CVD synthesis of MWCNTs. Carbon, 2007. 45(4): p. 833-838.

22. Orbaek AW, Aggarwal N, Barron AR. The development of a 'process map'for the growth of carbon nanomaterials from ferrocene by injection CVD. Journal of Materials Chemistry A, 2013. 1(45): p. 14122-14132.

23. Hasegawa K, Noda S. Moderating carbon supply and suppressing Ostwald ripening of catalyst particles to produce 4.5- $\mathrm{mm}$-tall single-walled carbon nanotube forests. Carbon, 2011.49(13): p. 4497-4504.

24. Xiang R, Einarsson E, Okawa J, Miyauchi Y, Maruyama S. Acetyleneaccelerated alcohol catalytic chemical vapor deposition growth of vertically 
aligned single-walled carbon nanotubes. The Journal of Physical Chemistry C, 2009. 113(18): p. 7511-7515.

25. He D, Li H, Li W, Haghi-Ashtiani P, Lejay P, Bai J. Growth of carbon nanotubes in six orthogonal directions on spherical alumina microparticles. Carbon, 2011. 49(7): p. 2273-2286.

26. Lehman JH, Terrones M, Mansfield E, Hurst KE, Meunier V. Evaluating the characteristics of multiwall carbon nanotubes. Carbon, 2011. 49(8): p. 2581-2602.

27. Schünemann C, Schäffel F, Bachmatiuk A, Queitsch U, Sparing $M$, Rellinghaus B et al. Catalyst poisoning by amorphous carbon during carbon nanotube growth: fact or fiction? ACS nano, 2011. 5(11): p. 8928-8934.

28. Mehedi H-a, Arnault J-C, Eon D, Hébert C, Carole D, Omnes F et al. Etching mechanism of diamond by Ni nanoparticles for fabrication of nanopores. Carbon, 2013. 59: p. 448-456.

29. Ohashi F, Chen GY, Stolojan V, Silva SRP. The role of the gas species on the formation of carbon nanotubes during thermal chemical vapour deposition. Nanotechnology, 2008. 19(44): p. 445605.

30. Vanpaemel J, van der Veen MH, Cott DJ, Sugiura M, Asselberghs Inge, De Gendt S et al. Dual Role of Hydrogen in Low Temperature Plasma Enhanced Carbon Nanotube Growth. The Journal of Physical Chemistry C, 2015. $119(32):$ p. 18293-18302.

31. Vlassiouk I, Regmi M, Fulvio P, Dai S, Datskos P, Eres G et al. Role of hydrogen in chemical vapor deposition growth of large single-crystal graphene. Acs Nano, 2011. 5(7): p. 6069-6076.

32. Ionescu MI, Zhang Y, Li R, Sun X, Abou-Rachid H, Lussier LS. Hydrogen-free spray pyrolysis chemical vapor deposition method for the carbon nanotube growth: parametric studies. Applied surface science, 2011. 257(15): p. 6843-6849.

33. Lee GD, Han S, Yu J, Ihm J. Catalytic decomposition of acetylene on Fe(001): A first-principles study. Physical Review B, 2002. 66(8).

34. Khalilov U, Bogaerts A, Neyts EC. Microscopic mechanisms of vertical graphene and carbon nanotube cap nucleation from hydrocarbon growth precursors. Nanoscale, 2014. 6(15): p. 9206-14. 
35. Mattevi C, Wirth CT, Hofmann S, Blume R, Cantoro M, Ducati C et al. In-situ $X$-ray photoelectron spectroscopy study of catalyst-support interactions and growth of carbon nanotube forests. The Journal of Physical Chemistry C, 2008. 112(32): p. 12207-12213.

36. Sakurai S, Nishino H, Futaba DN, Yasuda S, Yamada T, Maigne A et al. Role of subsurface diffusion and Ostwald ripening in catalyst formation for singlewalled carbon nanotube forest growth. Journal of the American Chemical Society, 2012.134(4): p. 2148-2153.

37. Kim DY, Sugime H, Hasegawa K, Osawa T, Noda S. Sub-millimeter-long carbon nanotubes repeatedly grown on and separated from ceramic beads in a single fluidized bed reactor. Carbon, 2011. 49(6): p. 1972-1979.

38. Xiang R, Luo GH, Qian WZ, Wang Y, Wei F, Li Q. Large area growth of aligned CNT arrays on spheres: towards large scale and continuous production. Chemical Vapor Deposition, 2007. 13(10): p. 533-536.

39. Ago H, Uehara N, Yoshihara N, Tsuji M, Yumura M, Tomonaga, N et al. Gas analysis of the CVD process for high yield growth of carbon nanotubes over metal-supported catalysts. Carbon, 2006. 44(14): p. 2912-2918.

40. Chiodarelli N, Richard O, Bender H, Heyns M, De Gendt S, Groeseneken G et al. Correlation between number of walls and diameter in multiwall carbon nanotubes grown by chemical vapor deposition. Carbon, 2012. 50(5): p. 1748-1752.

41. Jourdain V, Stéphan O, Castignolles M, Loiseau A, Bernier P. Controlling the morphology of multiwalled carbon nanotubes by sequential catalytic growth induced by phosphorus. Advanced Materials, 2004. 16(5): p. 447-453.

42. Hoecker C, Smail F, Bajada M, Pick M, Boies A. Catalyst nanoparticle growth dynamics and their influence on product morphology in a CVD process for continuous carbon nanotube synthesis. Carbon, 2016. 96: p. 116-124.

43. Leonhardt A, Hampel S, Mueller C, Moench I, Koseva R, Ritschel M et al. Synthesis, Properties, and Applications of Ferromagnetic - Filled Carbon Nanotubes. Chemical vapor deposition, 2006. 12(6): p. 380-387.

44. Kuwana K, Saito K. Modeling ferrocene reactions and iron nanoparticle formation: Application to CVD synthesis of carbon nanotubes. Proceedings of the Combustion Institute, 2007. 31(2): p. 1857-1864. 
45. Elihn K, Larsson K. A theoretical study of the thermal fragmentation of ferrocene. Thin solid films, 2004. 458(1): p. 325-329.

46. Dresselhaus MS, Jorio A, Saito R. Characterizing graphene, graphite, and carbon nanotubes by Raman spectroscopy. Annu. Rev. Condens. Matter Phys., 2010. 1(1): p. 89-108.

47. Behr MJ, Gaulding EA, Mkhoyan KA, Aydil ES. Hydrogen etching and cutting of multiwall carbon nanotubes. Journal of Vacuum Science \& Technology B, 2010. 28(6): p. 1187-1194.

48. Zhang R, Li B, Iovu MC, Jeffries-EL M, Sauvé G, Cooper J et al. Nanostructure dependence of field-effect mobility in regioregular poly (3-hexylthiophene) thin film field effect transistors. Journal of the American Chemical Society, 2006. 128(11): p. 3480-3481.

49. Bianco A, Cacciotti I, Fragalá ME, Lamastra FR, Speghini A, Piccinelli F et al. Eu-doped titania nanofibers: processing, thermal behaviour and luminescent properties. Journal of nanoscience and nanotechnology, 2010. 10(8): p. 5183-5190.

50. Moon SY, Ogasawara T, Hanamitsu S, Shioda K, Inoue Y. Efficient and Simple Surface Modification of Carbon Nanotubes by Dry Process Using hydrogen. Advanced Energy Materials, 2015. 17(8): p.1220-1225.

51. Lee C, Leconte N, Kim J, Cho D, Lyo IW, Choi EJ, Optical spectroscopy study on the effect of hydrogen adsorption on graphene. Carbon, 2016. 103: p.109114. 